\title{
Editorial: the evolving field of tangible interaction for children: the challenge of empirical validation
}

\author{
Bieke Zaman - Vero Vanden Abeele • \\ Panos Markopoulos • Paul Marshall
}

Published online: 12 June 2011

(C) Springer-Verlag London Limited 2011

\begin{abstract}
This special issue is devoted to the topic of tangible user interfaces and children. It emphasizes research on tangibility that transcends system descriptions, focusing on the empirical support of theories and design guidance. The papers result from the organization of a workshop at the CHI 2009 ACM conference in Boston, USA. As an introduction to this issue, empirical evidence is discussed for the potential benefits that using TUIs may have for children. Next, we focus on the impact of tangibility in terms of usability, learning, collaboration, and fun. Finally, we suggest directions for future work and outline the papers that are included in this special issue.
\end{abstract}

\footnotetext{
B. Zaman $(\square)$

Centre for User Experience Research (CUO),

Katholieke Universiteit Leuven, Parkstraat 45 Bus 3605,

3000 Leuven, Belgium

e-mail: Bieke.Zaman@soc.kuleuven.be

B. Zaman

Future Health Department, IBBT-K.U.Leuven,

Kasteelpark Arenberg 10 bus 2446, 3001 Leuven, Belgium

V. Vanden Abeele

e-Media Lab, GROUP T, Leuven Engineering College/CUO

(Association KULeuven), Vesaliusstraat 13,

3000 Leuven, Belgium

e-mail: Vero.Vanden.Abeele@groept.be

P. Markopoulos

User Centred Engineering Group, Department of Industrial

Design, Eindhoven University of Technology,

Den Dolech 2, 5612 AZ Eindhoven, the Netherlands

e-mail: p.markopoulos@tue.nl

P. Marshall

WMG, University of Warwick, CV4 7AL Coventry, UK

e-mail: paul.marshall@warwick.ac.uk
}

Keywords TUI · Children · GUI · Usability · Learning · Collaboration · Fun

\section{Introduction}

In the history of this young research field on tangible user interfaces and children, the concepts of tangible user interfaces and tangibility have fluidly evolved as a result of developments in technology and design. A host of related and overlapping terms and definitions for tangible user interfaces (TUIs) have become popular, such as graspable user interfaces [1], tangible bits [2], or tangible and embodied interaction [3]. Important as they may be, in this special issue, we shall not focus on the fine nuances and differences between such concepts. Instead, we adopt a broad perspective on tangibility that mirrors the continued emphasis of related design and research work on the physicality of interaction and the closeness of mapping between physical manipulations of the tangibles and the input/output semantics. The term tangible user interfaces is used here in accordance with Shaer and Hornecker's [4] definition: "Interfaces that are concerned with providing tangible representations to digital information and controls, allowing users to quite literally grasp data with their hand and effect functionality by physical manipulations of these representations."

The majority of research on tangibles has been innovation oriented. Researchers often explore the design space enabled by embedding computation in physical objects. A relatively large proportion of this type of research has concerned applications for children. The relevance of TUIs for children's education was pointed out even before the emergence of the term TUI, with the pioneering work on Mindstorms by Papert [5] where 
programming was associated with physical objects. This work has continued through several investigations, e.g., examining the design of robots [6] and educational toys for children, up to the more recent work on digital manipulatives from the Lifelong Kindergarten group at MIT (e.g., [7, 8]).

In addition to the educational relevance of tangibility for children, researchers have focused on its entertainment and usability potential as well. For instance, the I/O brush was introduced by Ryokai [9] as a novel and intuitive interface for coloring in digital painting applications. The interest of researchers in the role of physical interaction for children's entertainment goes back at least to the mid1990s. An early example is the Rosebud [10], where a stuffed animal was used by children to store and retrieve stories. In the discussion of the entertainment value of tangible interfaces, one should note that the boundary is quite blurred between a child's toy featuring some electronics and interactivity and what the research community might recognize as a TUI designed to support children's play.

Finally, a host of games for children featuring tangibility have also been introduced to encourage educational outcomes through collaboration (see for instance [11, 12]). Other benefits aimed for have been of a more social nature. For example, the pOwerball [13] was an augmented reality tabletop pinball game designed to encourage children with mixed abilities to have fun together and interact socially during the game.

While enthusiasm for TUIs and the widespread conviction that tangibility brings about additional value to users is anything but wavering, some researchers have started to comment on the lack of empirical evidence to support these assumed benefits [14-16]. These pressing issues motivated the organization of a workshop at the $\mathrm{CHI}$ 2009 ACM conference in Boston, USA. It led to the production of this special issue, which aimed to provide a more balanced view on the benefits of tangibility for children.

In particular, this editorial begins by summarizing the currently available empirical evidence regarding the potential benefits that using TUIs may have for children. We first focus on the empirical evidence for the usability benefits of tangible user interfaces with children, followed by a focus on the learning benefits and then the benefits for fun. While these are treated separately for reasons of clarity, there are potentially strong relationships between these three perspectives and issues relating to collaboration. Next, the empirical models of research that have been used to generate the claims about tangibility are discussed. Finally, we suggest directions for future work and outline the papers that are included in this special issue.

\section{Expectations from tangible interaction}

From the very early and pioneering work on tangibility, expectations have clustered around four areas. Firstly that tangibility has been associated with improved usability, generally linked to the naturalness of manipulating physical objects and capitalizing on users' innate skills. Secondly, it has been suggested that tangible user interfaces can bring about potential learning benefits to children, which may arise through links between concrete manipulations and cognition. Thirdly, tangible user interfaces are often considered to be more fun to use than more traditional kinds of interfaces, due to the physicality of the interaction and perhaps the increased visibility. Finally, it has been claimed that TUIs may offer benefits in terms of collaboration, a benefit that often serves as a catalyst for the expectations mentioned above. The facilitation of collaboration through tangible interaction can arise from having shared and equal access to interacting with a system.

In the sections below, we examine the rationale for the usability, learning, fun, and collaboration claims (and additionally on social interaction) about the use of TUIs by children and critically review the related evidence available to date.

\subsection{The empirical basis for usability benefits of tangibility}

Several reasons have been put forward to argue for the superior usability of TUIs. In particular, TUIs are characterized as having the following features, which have the potential to improve a product's user friendliness:

(a) Specificity of input devices, which reduces modality on the interface $[1,4,17]$

(b) Improved accessibility of the interaction [8], building on everyday skills and experiences of the physical world $[18,19]$

(c) Employment of bi-manual [1] and haptic interaction skills [20]

(d) Facilitation of spatial tasks through the inherent spatiality of TUIs [1, 21, 22]

(e) Tight coupling of control of the physical object and the manipulation of its digital representation $[2,20]$

Despite the interest the research community has shown in the user friendliness of tangible user interfaces, empirical evidence remains scarce. Most studies that deal with these characteristics have discussed product use for adults. For example, Fitzmaurice and Buxton [23] contrasted graspable user interfaces, where each physical device was specifically assigned to one logical function, with traditional graphical user interfaces, where the user was required to assign the 
physical input device to a logical device in the user interface. They described this contrast by focusing on the evocative discrepancy between "space multiplexing" and "time multiplexing". Their results showed how removing an additional interaction step through tangible interaction improves speed and efficiency. Furthermore, Patten and Ishii [21] compared how people use space to organize information while using TUIs and GUIs. Their findings suggested that TUIs encourage the use of spatial organization as a mnemonic of relationships between items, which in turn encourages recollection. Another example is the study carried out by Jacob et al. [24] who compared several alternative interaction techniques for organizing information in space, showing how a TUI can be more efficient than a GUI. TUIs are often argued to support bi-manual input as well; some authors have pointed toward the performance advantages of and subjective preference for TUIs over a touch-based interface, [25], whereas others found no superiority of TUIs when compared with touchbased interaction in terms of user subjective preferences, (e.g., [26]).

Studies that focused on the potential usability advantages of tangibility for children have generally pointed toward the same hypothesized advantages of TUIs listed for adults. For instance, many researchers have also argued that TUIs are more natural and intuitive to children (see e.g., $[1,8])$ because they are based on affordances known from everyday interaction with the real world. Even though the difficulties young children may have with traditional input devices have been thoroughly discussed (e.g., [27]), no additional reasons have been given to explain why especially young children would benefit from tangible interaction. Research demonstrating usability benefits of tangibility for children is sparse. Also, the evidence to support this argument is inconclusive. For instance, Verhaegh et al. [28] showed that for a game involving spatial manipulation of objects, the TUI was more usable for children aged 5-7 than a point and click graphical interface. However, Abeele et al. [29] compared the usability of controlling a game via manipulations with a cuddly toy interface with presses on a keyboard and concluded that children were more effective and efficient with the traditional interaction paradigm.

Overall, a review of the studies that discuss the potential of tangible interaction with respect to interaction usability reveals that the majority are concerned with the benefits of tangibility for adults. Less is known regarding how tangibility can lead to greater usability for children. The majority of studies illustrate some optimism which so far is not sufficiently founded on empirical evidence. More research is needed to expose not only the potential usability advantages but also the disadvantages of TUIs for children, in which contexts and for what kind of activities.
2.2 The empirical basis for learning benefits of tangibility

Research on tangible interaction has from the very beginning focused on the potential of novel digitally augmented physical artefacts to support learning. Early toolkits such as Resnick's digital manipulatives [7] and Eisenberg et al's [30] computationally enhanced construction kits were motivated by a constructionist philosophy. These kits provided children with tools to support creative exploration of concepts related to materials, structures, and computation. Newer toolkits such as Buechley et al's Lilypad Arduino have continued this tradition [31].

Other projects have aimed to support more focused learning about concepts such as narrative, programming, or system dynamics. Such work is typically premised on broad educational theories, which have been interpreted as suggesting that physical manipulation of artefacts might be particularly beneficial for learning: the use of concrete manipulatives as advocated by Froebel [32] and Montessori [33], Piaget's theory of cognitive development as the progressive abstraction from sensorimotor experience (e.g., [34]), Bruner's [19] description of enactive learning, and "hands-on learning" (cf. discussion in O'Malley and Stanton Fraser [16]).

Early exploratory work on TUIs for learning prioritised technical innovation over empirical validation or theoretical development [35]. However, while a number of trends developed in the literature on tangibles for learning, there has been little empirical validation of assumptions about the learning benefits of tangible interfaces and little theoretical development beyond framing this work with respect to broad-brush educational theories [14]. Moreover, recent research in the learning sciences has questioned the supposed learning benefits of using mathematics manipulatives (e.g., [36]) and physical materials more generally $[37,38]$.

The challenge of providing empirical and theoretical validation for this work remains. Furthermore, as with research on tangibles and usability, research that has empirically explored tangible interfaces for learning, has focused mainly on adults rather than children [39, 40]. So far, related work on measuring learning benefits of tangibles for children did not successfully manage to provide conclusive evidence [41].

While many questions remain open, work is beginning to emerge that attempts to both better articulate mechanisms by which tangibles might support learning and for whom and that aims to provide empirical support for this emerging theoretical work. Some progress has been made in understanding the role that the representational and manipulative properties of different tangible artefacts might play in influencing learning and problem-solving 
strategies. Manches et al. [39] focused on physical properties of mathematics manipulatives, documenting differences in numerical partitioning strategies for paper, physical objects, and a mouse-controlled graphical interface. Wyeth [42] described how young children were able to demonstrate understanding of some fundamental programming concepts using stackable Electronic Blocks. Price [43] outlined a conceptual framework for investigating how different ways of linking digital information with physical objects might influence interaction and cognition and thus impact upon learning. In subsequent work, Price et al. [44] provided empirical evidence that the location of the digital representation in a tangible interface can influence the level of abstraction used to represent a concept.

A number of new theoretical perspectives have been adopted to support the design and analysis of tangible interfaces. Antle et al. [45] used Kirsh and Maglio's [46] notion of epistemic and pragmatic actions to analyze children's problem-solving strategies on a jigsaw puzzle task: Epistemic actions are those which change the nature of the problem-solving task, whereas pragmatic actions bring one physically closer to a goal. Children carried out more exploratory epistemic actions on this spatial task when using tangible artefacts than when using a mouse, which although it was primarily a problem solving rather than a learning task may have implications for the design of future tangible systems. Thus, different tangible artefacts can be shown to potentially influence processes related to learning, although these have not yet been shown to lead to measurably different learning outcomes. New theoretical work has also started to emerge that applies theories of embodied conceptual metaphor to design systems to support learning about abstract qualities of sound. This involves mapping physical movements of the body to abstract sound parameters such as pitch and amplitude [41, 47] and has shown some promise in facilitating learning.

A further development in empirical work on tangibles and learning is in the support of groups with special educational needs. Farr et al. [48] described how a group of children on the autistic spectrum engaged in more social activities (i.e., more co-operative play, on-looking, and parallel play) when playing with Topobo, a tangible construction kit with kinetic memory, than when playing with conventional Lego. Similarly, Farr et al. [49] showed how a configurable narrative play set, the Augmented Knights Castle, encouraged more collaborative play and less solitary play in a group of children on the autistic spectrum than a non-configurable version of the same set. Garzotto and Bordogna [50] have experimented with augmenting existing low-tech paper materials used in schools with children with severe cognitive, linguistic, and motor disabilities so as to link them with multimedia resources. In a sustained design-based approach, they have highlighted a number of potential emotional, cognitive, and motor control learning benefits as well as benefits for non-disabled children involved in the design process. Hengeveld et al. [51] examined how tangible interaction could support shy children in developing social skills and being accepted by their peers. Hengeveld et al. [51] developed a tangible application for toddlers (ages 1-4) with multiple disabilities. They claimed multiple benefits that they attributed to tangibility, e.g., that the TUI is closer to a toddler's usual style of exploration, that the interface slowed down their interaction allowing more control over its timing, and that it provided more opportunities for facial, gestural, and verbal expressions by the children. These statements were based on weekly 30-min sessions with 15 children, for a period of 6 weeks. However, the methodology used (retrospective interviews with speech therapists and questionnaires after 6 weeks and no related observations and quantitative analysis) indicates that the conclusions should be treated with some caution.

Few other tangible learning projects have moved out of controlled laboratory or school settings. One notable exception is the work of Horn and colleagues [52], who investigated the use of simple robust tangible programming elements in a science museum, observing how visitors were more likely to use the tangible interface than a graphical equivalent, how they tended to use it for longer, and how children were more likely to get involved in using the tangible interface. A second example is the Topobo system, which has been field tested with a large number of educators working across a broad spectrum of age ranges and contexts. Parkes et al. [53] provided a high-level overview of this work discussing the complex interdependencies between context, age range, and the time spent working with the system, which influence the success of implementing this system into education.

Thus, there have been interesting developments in work focusing on the putative learning benefits of tangibles in recent years. Most research has focused on the effects of using different kinds of tangible materials on individual and collaborative learning processes rather than on the learning outcomes. However, there have so far been few compelling demonstrations of the benefits of tangibility on learning outcomes. Only a partial picture of the strengths and weaknesses of different kinds of tangible technologies for different kinds of learning activities and different user groups has been drawn.

\subsection{The empirical basis for fun benefits of tangibility}

Extending beyond instrumental benefits such as usability or learning, many TUI design projects have also aimed to provide non-instrumental benefits, pertaining to enjoyment, 
playfulness, esthetics of interaction, or flow experiences. One could argue that TUIs extend the functional and aim to provide hedonic benefits [54]. In fact, tangible interaction has often been linked to an improved user experience, which in this special issue is described under the umbrella term of "fun". Many TUIs targeted at children have been inspired and justified by the hypothesis that graspable, physical interactions with close mappings between the digital and real world are simply more fun.

Defining an umbrella term such as fun is, however, not a straightforward matter. Each framework or theory has involved its own characteristic perspective on the entertainment value of technology interactions. For example, the GameFlow model put forward by Sweetser and Wyeth [55] highlighted feelings of challenge, control, and immersion; the framework described by Takatalo [56] paid attention to flow experiences and immersion; the pleasure typology proposed by Jordan [57] distinguished between socio-, physio-, psycho-, and ideo-pleasure; the judgemental model developed by Hassenzahl [54] brought the hedonic product characteristics into focus, distinguishing between stimulation, identification, and evocation; and Norman's [58] model for emotional design focused on the user's emotions, identifying three levels for emotional design: the visceral, behavioral, and reflective. The listed frameworks and models are by no means exhaustive but only serve to illustrate the diversity in approaches to designing for the fun aspects of the interaction.

The variety in perspectives on what constitutes fun has put up serious barriers to identifying one common approach for the empirical validation of the entertainment value of tangible interactions. The choice of framework or perspective greatly influences the research methods and hypotheses that are put forward by researchers. For instance, we encounter theoretical scholars who define fun user experiences as a multidimensional construct [59] in contrast to empirical researchers who tend to rely on onedimensional definitions (e.g., [60-64]). In addition to that, user experience can be considered as a process of interaction to be observed (e.g., [65]); as a physiological response to environmental stimuli to be measured via physiological measures (e.g., [66-68]); or as an outcome or user experience evaluation, measured for instance via selfreport measures (e.g., [62]).

Finding a way through these theoretical frameworks and methodological approaches is challenging, and relating these to a young research population for the evaluation of tangible interaction confronts us with even a more ambitious endeavor. In this journal issue, Faber and van den Hoven rose to the challenge by applying Flow theory in their research in order to increase the fun experience of shooting marbles for youngsters. By optimizing the underlying dimensions (i.e., clear goals, more control, and feedback), they improved upon their design. At the same time, they provided researchers with an insight into what constitutes fun when shooting marbles. We argue that in order to move the field on tangible interaction and children forward, more of these insights are necessary to understand the mechanisms underlying experienced fun.

We might for instance refer to Jordan's pleasures framework and expect that TUIs in particular offer physiopleasure [57]. In this context, Bianchi-Berthouse [69] for example experimented with the guitar-shaped controller used when playing Guitar Hero (by Activision) and found that participants reported great immersion and enjoyment when required to make full body movements. "Body and Senses" was also put forward as a source of fun for preschoolers in Zaman and Vanden Abeele's likeability framework [70]. Furthermore, the importance of sensory experiences was emphasized by Soute et al. [71] who focused on physical activity and Wyeth [72] who reported on young children's immersion and personal connectedness while enjoying the exploration and sensory discovery of artistic artefacts.

Nevertheless, in the literature on the entertainment value of tangible interaction, it still remains unclear how the mechanisms of physical action relate to the perceived fun. Hypotheses are formulated, for instance by Sweetser and Wyeth [55] and Soute et al. [71] who have postulated that in their studies "fun" was derived from social interaction and collaboration rather than mere physical action. Furthermore, Lindley et al. [64] found that movement can stir up the experience of game play via the effects on engagement and social interaction. Overall, these studies indicated that the physicality and visibility of tangible interactions foster social interaction and collaboration, which in turn provides fun. Social interaction or "social fun" so far seems to be the most important benefit of TUIs in many empirical evaluations.

Studies on TUIs and adults have emphasized the importance of "natural mappings" associated with tangibles, with respect to feelings of presence (immersion in a virtual environment) underlying fun. Skaski et al. [60] found that playing games with a steering wheel controller resulted in more feelings of presence, flow, and enjoyment than playing the same game with traditional controllers that provided less natural mappings. Similarly, Johnson et al. [73] compared playing a surfing game by standing on a surfboard with playing via a classic controller, finding that participants reported greater fun when interacting via the physically controlled peripheral. In these studies, the perceived naturalness of interaction and resulting immersion was suggested as the underlying factor contributing to greater fun.

We should be aware, however, that the data on the fun benefits of tangibility are equivocal. For instance, in 
contrast to the optimistic results revealed in the studies mentioned elsewhere, Limperos et al. [74] and Abeele et al. [62] could not find evidence that natural mappings are necessarily contributing to greater enjoyment when playing games, because of a lack of precision and control experienced by the player. The same observation was also made by Bowman and Boyan [75]. These findings suggest that although TUIs are found to contribute to "perceived naturalness" by offering physical actions and natural mapping, they may equally decrease "perceived precision" or control as compared with classic interaction schemes and controllers.

In sum, the empirical basis for the fun benefits of tangibility is in a similar preliminary phase as the empirical basis for its usability and learning benefits. A variety of underlying mechanisms (e.g., physio-pleasure, flow, presence, or social interaction) that could lead to increased fun have been suggested but these remain rather ill defined. In the current state-of-the-art, the described impact of tangibility remains speculative and lacks empirical validation. Consequently, the field on tangible interaction would benefit from more empirically grounded demonstrations of benefits and from studies that explain what these benefits might imply for young users.

\subsection{The empirical basis of collaboration benefits of tangibility}

In several studies, different kinds of tangibles have also been shown able to influence collaborative interactions. Using a design-based research approach, Ferneaus and Tholander [76] described some potential social affordances of interactive physical objects. They showed how these objects were used flexibly both inside and outside of an interactive programming space to plan and organize collaborative activity. Marshall et al. [77] detailed qualitative differences in ways that children negotiated access to resources when using (unaugmented) physical objects and digital objects on a multitouch interactive surface. In particular, they found that with the physical materials, disputes were resolved more subtly by blocking access to the object or moving it out of reach. Price et al. [78] discussed the impact of different kinds of tangible interaction mechanisms on group behavior and discussed potential influences on learning. In a paper by Hornecker and Buur [79], it was argued that the visibility of the tangible interaction made the physical actions "legible" to others, enabling parallel input from multiple adult users. Suzuki and Kato [80] showed observational evidence for the affordances of physicality by describing how children utilized body movement and positioning in their collaboration. Another example is the pOwerball study [13], which was successful in exemplifying how social interaction in and around the game was triggered among children. Nevertheless, the success of the pOwerball system could not directly be attributed to the tangibility of the objects. The same can be said of many other design projects, which were evaluated as a whole, not attempting to isolate the impact of tangibility, such as for instance the StoryMat study [81] or the Ely the Explorer study [11].

In sum, a rudimentary picture of the empirical basis of collaboration benefits of tangibility has been provided. Although many design projects would benefit from isolating the impact of tangibility, we should also acknowledge that work is beginning to emerge that outlines some of the ways that tangible interaction mechanisms can influence group behaviors, impacting collaborative learning.

\section{Research paradigms for tangibility}

In researching the assumed benefits of tangibility, it is important to gain insight into how the assumed benefits of tangible interaction might be evaluated. In the same way that the theoretical lens determines what insights we can gain on tangible interactions, so does the chosen evaluation methodology impact the type of results we reveal. In this section, we suggest a classification of research paradigms that are currently used in understanding, evaluating, and designing tangible interaction. We make a methodological distinction between the design and evaluation of tangible interaction depending on the research agenda. More specifically, we distinguish between single case evaluation studies, comparative evaluation studies, and design case studies. In what follows, examples are provided for each of these three research paradigms. Furthermore, the paradigms' relevance is discussed with regard to research practices on tangible interaction for children.

\subsection{Single case evaluation studies}

The general optimism regarding the value of tangible interaction for children is fueled by small-scale, single case studies. Single user experience studies are vulnerable to oversimplifying children's typically positive reactions. For instance, in the single evaluation studies of Weller et al. [82] or Scharf and their colleagues [83], it was concluded, respectively, that all children "liked it a lot" [82] and that the tangible object was "a lot of fun" [83]. Some researchers have even claimed the superiority of tangible interaction in a single evaluation study. For instance, Johnson and colleagues [84] reported that plush toy interaction provided more emotional contact.

While very useful in exploring a new design space or building hypotheses, the problem with single evaluation studies is that it is not always clear what effects can be 
expected and what accounts for the positive effects (see e.g., [85]). Did children like it because they enjoyed the tangible interaction or did they rather enjoy the product's graphics and design? Or did children just report positive evaluations because of external reasons, for instance the fact that they were "withdrawn" from normal school activities to participate in the evaluation study, being given extra attention (and sweets)?

Single case evaluation studies do not generally challenge the value of tangibility; neither do they aim to critically question the design rationale. Instead, their research aims are concerned with finding and evaluating the right design and product characteristics, giving just a simple account of the successful and less successful aspects of the design. As a consequence, one may wonder whether these single case studies would report similar positive evaluations of the product if a comparative research design was used in which the tangible object is compared with a nontangible interaction-based object. This can lead to surprising results. For example, Abeele and colleagues [29] found that contrary to their expectations, a tangible interaction game was less likeable than a comparable keyboard interaction game. The same goes for the learning benefits of tangibility. A comparative study may cast a different light on the assumed benefits of tangibility. For instance, this journal includes an overview of studies carried out by Horn and his colleagues in which tangible interaction offered advantages as well as studies where tangible interaction proved less useful than alternative interaction styles.

In sum, single case evaluation studies often lack the analytical leverage that is needed to detail and evidence the benefits of tangibility. However, if designed and reported well, they can illustrate unusual, innovative benefits of tangibility especially when rich qualitative accounts are provided of how design aspects are conducive to different patterns of behavior and different types of experiences.

\subsection{Comparative evaluation studies}

Comparative studies are often instructive, for instance to benchmark products or to provide evidence of the advantages of one interaction style over another. In comparative research, some researchers explicitly focus on several types of tangible interactions for one prototype (e.g., [86]) whereas others mainly deal with the perceived differences between graphical user interface (GUI) interactions and tangible interactions. To illustrate, Fails and his colleagues [87] compared children's user experiences with a desktop versus a physical interactive environment. Additionally, this journal provides good examples of comparative evaluation studies: Sylla and her colleagues report on a study that compared children's attitudes toward a tangible versus a traditional user interface to reveal the most effective approach to stimulate preschoolers toward good oral hygiene. Also in this journal, Horn and colleagues explain the results of a museum study in which children's interactions and evaluations with a tangible and mouse-based programming were compared.

Moreover, some studies do not only focus on the interaction input styles but also upon the output constellations, such as for instance Wyeth's study [88]. In Gottel's study [89], the author even designed a more complex comparative research design to evaluate the Props on Board Navigation and Orientation (ProBoNO) environment. He not only focused on the effect of two types of input levels (cursor/mouse versus ProBoNo) and haptic feedback choices (with or without guidance) but also upon two types of presentations (board game versus virtual environment) [89].

As stated before, comparative evaluation studies have the potential to provide more confidence regarding claims for tangibility. However, comparative studies are only instructive if the alternative is "meaningful". Given the intellectual legacy of the field of Human-Computer Interaction, TUIs are often discussed in juxtaposition to traditional input/output devices that characterize contemporary graphical user interfaces (GUIs), relying on windows, icons, menus, pointers, etc. It is in relation to these traditional and widespread forms of interaction that researchers have typically attempted to articulate and demonstrate the benefits of tangibility. Nevertheless, in comparing TUIs and GUIs, one should guard the results' ecological validity. In studies where the product in question was originally designed with tangibility as an essential part of the user experience, the alternative for the TUI runs the risk of becoming no more than a "damaged" counterpart. For instance, in the comparative evaluation study by Metaxas and colleagues [90], a rather forced alternative was created to evaluate the potential of their game-controlled physical toy cars, versus virtual cars as projected renderings in an augmented reality environment.

Comparison to a damaged version limits the extent to which the conclusions can be generalized to different design contexts. Moreover, all too often there are too many "variables" that are changed as GUIs and TUIs are different in several ways, including the representation characteristics, the problem-solving strategies that are demanded, the nature of physical action required, etc. Unfortunately, many comparisons of TUIs with GUIs lack external validity, ignoring the radically different design space each type of interaction is offering. An alternative approach, aiming to have more relevance to design at the cost of experimental control, was presented by Soute et al. [71]. They compared two versions of the same game concept for which two credible alternatives were implemented 
to evaluate the game's interaction potential. However, they introduced numerous differences between the two games other than the physicality of the game object.

Nevertheless, even in these more rigorously setup comparative studies, one cannot control for all intervening parameters. For instance, there may be a novelty effect that makes children favor TUIs over GUIs. Furthermore, as argued in [91], many of the advantages initially associated with tangibility are in fact inherent in multitouch displays, and we could add to most shared interactive surfaces. Consequently, the argument for tangibility often has to be weakened or at least be nuanced in relation to what it is compared with and in what particular context. One should then consider distinguishing between the physicality of the interface and interaction versus the bi-manual input, horizontal shared displace. Even in these cases, the choice between tangibility and an interactive surface is very much context bound and task specific.

To summarize, there are drawbacks and possible risks for each comparative evaluation study. This is a phenomenon that is, perhaps, inherent in the field of Human-Computer Interaction, where research is typically characterized by a multitude of factors that may influence the interaction process, its outcomes, and the perception of it. Hence, finding the right research paradigm to be able to generalize research findings is a real challenge. Often, research findings in this field can only account for the situation in which they are revealed. For comparative evaluation studies, this implies that the findings are only generalizable for the particular products involved, the interaction styles concerned, and the specific context in which these products were used. In order to enable generalizable conclusions regarding the benefits or costs of different aspects of tangibility, empirical comparisons need to be better linked to theoretical abstractions of tangibility. For example, the comparison of concepts such as time multiplexing to space multiplexing by Fitzmaurice, Ishii, and Buxton [1] can provide higher analytic leverage than evaluating specific systems holistically.

\subsection{Design case studies}

The last research paradigm concerns design case studies. These may involve formative user evaluations that typify user-centered design practices, or they may be reflective accounts, elaborating design choices, and rationale in context. Evaluation studies may have a comparative element (when different options are compared during development) but can also involve single case evaluations characterizing different iterations within a design process.

Design case studies can by their nature serve at least two different purposes: to motivate a specific design innovation or, if reported appropriately, to instruct designers regarding design choices made in the context of the case at hand. For example, Verhaegh et al. [28] report the design of Camelot by motivating different steps of the design process with small-scale user studies. Particularly instructive are comparisons where the choices made regarding TUI design are novel problems and resonate with other designers in the field. For example, in this special issue, Bakker and colleagues report on the different design alternatives, from low-fidelity prototypes to high-fidelity prototypes that were compared and tested with children to inform the design of an engaging and effective interactive learning system with multiple embodied metaphor-based mappings. Also in this journal, Horn and colleagues document in detail how and why they evolved a hybrid prototype called Tern that children can use to (learn to) program graphically or tangibly. Further, Faber and colleagues explain how and why they follow a similar path in continuously and iteratively evaluating several prototypes of the MARBOWL prototype in distinct settings in order to increase children's fun experience of shooting marbles. The latter researchers also carried out a comparative evaluation of a "real" versus a "virtual" perspective, as they aimed to elaborate the existing, "traditional" game elements of shooting marbles in order to inform the design of a new, more engaging and fun digital marble game. It may also be that the focal point of comparison is temporal, as for instance in Gottel's study [89] in which children's experiences were compared at three moments over a period of 3 weeks.

Although less useful in isolating the advantages or disadvantages of the tangible interaction, design case studies tend to be very informative for designers. To exemplify this, Kirk et al. [91] provided a reflective account of their design, which was instructive in giving an idea of what were the actual problems facing TUI designers beyond the choice of tangible versus physical and without necessarily playing the role of "design rules" or "design guidelines" that one might expect to derive from empirical studies. Despite their high relevance, generalization from design case studies is difficult, as many of the reflections presented remain subjective conjectures of the researchers/designers or contextualized findings. To illustrate, in this journal, Manches and O'Malley reflect upon the relativity of physical learning materials, stressing that the symbolic significance of manipulatives is only granted by the context in which they are used.

No matter which methodological approach is chosen to research the benefits of tangibility, one should critically reflect on the context dependency of the results. Often, during formative evaluation studies, the tangible interaction protocols are compared against previous versions of the same product so that one can only decide upon improvements for that particular interaction, product, and context. In single case evaluation studies, there is no 
benchmark against which the product is compared, which makes it problematic to get hard evidence on the benefits of tangible interaction. Even when a comparative research paradigm is followed, prudence is called for to generalize the findings to other contexts than the evaluation study, especially when carried out within the truncated context of the experimenter's laboratory. User experience evaluations are always subjective because they reflect how certain product features or product interactions are perceived by the users in a particular context of use. It always concerns a momentary feeling of interacting with a product that may differ in other settings, at other moments, when other people evaluate it or when other alternatives are involved. Realizing the context dependence of the potential of tangible interaction is not only important in terms of user experience but also important to understand the product's learning, usability, or collaboration benefits.

\section{Conclusion}

This editorial has called for caution in relation to an a priori assumed superiority of tangibility. A more balanced approach is advocated, which documents not only the potential advantages but also the disadvantages of tangibility for children. The importance of the experimental and design context was also emphasized, arguing that researchers could reflect more on the contingency of the benefits of tangibility and consider external factors inherent in their evaluation context.

We have reviewed strengths and weaknesses of different types of studies that document the benefits of tangibility for children: single case studies, comparative evaluations, and design cases. In order to draw sound and generalizable conclusions from related studies, we advised going beyond the idea of TUIs as the antithesis of GUIs, especially when comparative evaluations are made, arguing instead for a closer link with theoretical abstractions (e.g., the various theoretical frameworks that have been proposed to characterize tangibility, see for instance [92]) and for more scientific rigor in empirical studies. Recognizing that rigor often trades off with relevance, we have argued in favor of reflective design cases and formative evaluations that expose what are actual choices facing designers beyond the dilemma of "tangible versus virtual". Above all, understanding the full impact of tangibility in design and evaluation studies is only possible through a variety of studies with different research models ranging from experiments to ethnographic studies, action research, and design-based research as well as through triangulation or cross-examination of methods.

In this journal, we selected empirical papers that report upon studies that gain complementary insights into children's perceptions of tangible interaction, that aim to design for the best tangible fun, and that picture the full impact of tangibility in a more valid way, preventing oversimplified conclusions.

(1) In an extensive program of research, Horn, Crouser, and Bers reported upon three studies in which the Tern prototype was iteratively evaluated and improved. Input was gathered via comparative studies, focusing upon the use of Tern in several settings such as museums, schools, or summer camps while also comparing tangible, graphical, and hybrid interactions. In these studies, several complementary methodological approaches were followed involving among others observations, questionnaires, one-onone and show-and-tell interviews, the use of photographs, the collaboration web or "thank you" web, video recordings, student work with children and teachers, and loggings.

(2) From a Flow model analysis perspective, Faber and van den Hoven combined questionnaires, field studies, co-design, concept evaluations with experts, prototypes, and comparative evaluations to understand how children evaluated Marlbow, a shooting marbles game.

(3) In Manches and O'Malley's paper, key debates about the representational advantages of manipulatives were summarized under two key headings: offloading cognition-where manipulatives may help children by freeing up valuable cognitive resources during problem solving and conceptual metaphors-where perceptual information or actions with objects have a structural correspondence with more symbolic concepts.

(4) In the paper of Sylla and her colleagues, the results of questionnaires with parents, interviews with children, and children's drawings were triangulated to analyze whether a tangible interface really accounted for a positive user experience and for learning effects.

(5) Bakker, Antle, and van den Hoven designed a comparative evaluation study and combined prototype testing, observation, and interviews to inform the design of tangibles for the manipulation of sounds.

(6) Finally, in Vanden Abeele and Zaman's paper, the authors reported upon a three-step comparative evaluation study that relied upon observation, a Thisor-That questionnaire and laddering interviews to understand and reveal the reasons for preferences of three types of cuddly toy interactions in a 3D game.

Together, we hope that this selection of papers will inspire interested readers and TUI researchers to further the field by yielding empirical evidence regarding the learning, usability, collaboration, and fun benefits of tangible interaction. 
Acknowledgments This editorial would not have been possible without the quantity and quality of the submissions of workshop participants at the workshop Tangibles and Children, at CHI 2009 in Boston, MA. During this event, both empirical challenges and failures of TUI prototypes were much debated, which inspired and convinced us of the necessity of this editorial.

Additionally, we would like to thank our reviewers for giving their time to make this special issue possible: Alissa Antle, Emilia Barakova, Wolmet Barendregt, Marina Bers, Sumitra Bhat, Bert Bongers, Nopporn Chotikakamthorn, Will Farr, Frank Feltham, Ylva Fernaeus, Rowanne Fleck, Franca Garzotto, Anne-Marie Hansen, Mike Horn, Eva Hornecker, Jörn Hurtienne, Evangelos Karapanos, Lars Knudsen, Mitja Kostomaj, Andy Manches, Javier Marco, Jean-Bernard Martens, Narcís Parés, Jabe Piterfaber, Karolien Poels, Allessantro Pollini, Taciana Pontual Falcao, Sara Price, Jochen Rick, Yvonne Rogers, Orit Shaer, Iris Soute, Jannienke Sturm, Sriram Subramanian, Cristina Sylla, Jakob Tholander, Marleen Van Vuchelen, Janneke Verhaegh, Peta Wyeth, Lana Yarosh, and Oren Zuckerman.

Particular thanks go to Eva Hornecker and Elise van den Hoven, who critically reflected on our statements in this editorial, contributed to the selection of research studies, and resigned to having us define tangible interaction the easy way.

\section{References}

1. Fitzmaurice GW, Ishii H, Buxton WAS (1995) Bricks: laying the foundations for graspable user interfaces," In: Proceedings of the SIGCHI conference on human factors in computing systems, Denver, Colorado, United States, pp 442-449

2. Ishii H, Ullmer B (1997) Tangible bits: towards seamless interfaces between people, bits and atoms

3. Dourish P (2001) Where the action is: the foundations of embodied interaction. MIT Press, Cambridge, MA, US

4. Shaer O, Hornecker E (2010) Tangible user interfaces: past, present, and future directions. Found Trends Hum Comput Interact 3:1-137

5. Papert S (1980) Mindstorms: children, computers, and powerful ideas. Bas, Cambridge, MA, USA

6. Druin A, Hendler JA (2000) Robots for kids: exploring new technologies for learning. Morgan Kaufmann Publishers Inc., San Francisco, CA, USA

7. Resnick M et al. (1998) Digital manipulatives: new toys to think with. In: Proceedings of the SIGCHI conference on human factors in computing systems, New York, NY, USA, p 281-287

8. Zuckerman O, Arida S, Resnick M (2005) Extending tangible interfaces for education: digital montessori-inspired manipulatives. In: Proceedings of the SIGCHI conference on human factors in computing systems, New York, NY, USA, p 859-868

9. Ryokai K, Marti S, Ishii H (2004) I/O brush: drawing with everyday objects as ink. In: Proceedings of the SIGCHI conference on human factors in computing systems, New York, NY, USA, p 303-310

10. Glos JW, Cassell J (1997) Rosebud: a place for interaction between memory, story, and self. In: Proceedings of the 2nd international conference on cognitive technology (CT luc0lu 8217\{\}97), Washington, DC, USA, p 88

11. Africano D, Berg S, Lindbergh $K$, Lundholm P, Nilbrink F, Persson A (2004) Designing tangible interfaces for children's collaboration. In: CHI luc0lu8217\{\}04 extended abstracts on human factors in computing systems. New York, NY, USA, pp 853-868

12. Sluis RJW, Weevers I, van Schijndel CHGJ, Kolos-Mazuryk L, Fitrianie S, Martens JBOS (2004) Read-it: five-to-seven-year-old children learn to read in a tabletop environment. In: Proceedings of the 2004 conference on Interaction design and children: building a community, New York, NY, USA, pp 73-80

13. Brederode B, Markopoulos P, Gielen M, Vermeeren A, de Ridder $\mathrm{H}$ (2005) pOwerball: the design of a novel mixed-reality game for children with mixed abilities. In: Proceedings of the 2005 conference on Interaction design and children. New York, NY, USA, pp 32-39

14. Marshall P (2007) Do tangible interfaces enhance learning? In: Proceedings of the 1st international conference on tangible and embedded interaction. New York, NY, USA, pp 163-170

15. Xie L, Antle AN, Motamedi N (2008) Are tangibles more fun?: comparing children's enjoyment and engagement using physical, graphical and tangible user interfaces. In: Proceedings of the second international conference on tangible and embedded interaction (TEI'08). Bonn, Germany, pp 191-198

16. Malley CO, Stanton Fraser D (2005) Literature review in learning with tangible technologies. Policy 11:1-52

17. Fitzmaurice GW (1996) Graspable user interfaces. Computer Science Dissertation, University of Toronto

18. Gibson JJ (1977) The theory of affordances. In: Perceiving, acting, and knowing: toward an ecological psychology, Lawrence Erlbaum, New Jersey

19. Bruner JS (1966) Toward a theory of instruction. Harvard University Press, Cambridge, MA, USA

20. Ishii $H$ (2008) Tangible bits: beyond pixels. In: Proceedings of the 2nd international conference on tangible and embedded interaction, New York, NY, USA, pp xv-xxv

21. Patten J, Ishii H (2000) A comparison of spatial organization strategies in graphical and tangible user interfaces. In Proceedings of DARE 2000 on designing augmented reality environments, New York, NY, USA, pp 41-50

22. Sharlin E, Watson B, Kitamura Y, Kishino F, Itoh Y (2004) On tangible user interfaces, humans and spatiality. Pers Ubiquit Comput 8:338-346

23. Fitzmaurice GW, Buxton W (1997) An empirical evaluation of graspable user interfaces: towards specialized, space-multiplexed input. In: Proceedings of the SIGCHI conference on human factors in computing systems, New York, NY, USA, pp 43-50

24. Jacob RJK, Ishii H, Pangaro G, Patten J (2001) A tangible interface for organizing information using a grid. In: Proceedings of the SIGCHI conference on human factors in computing systems: changing our world, changing ourselves (CHI '02). Minneapolis, Minnesota, USA, pp 339-346

25. Lucchi A, Jermann P, Zufferey G, Dillenbourg P (2010) An empirical evaluation of touch and tangible interfaces for tabletop displays. In: Proceedings of the fourth international conference on tangible, embedded, and embodied interaction, New York, NY, USA, pp 177-184

26. Terrenghi L, Kirk D, Richter H, Krämer S, Hilliges O, Butz A (2008) Physical handles at the interactive surface: exploring tangibility and its benefits. In Proceedings of the working conference on advanced visual interfaces, New York, NY, USA, pp 138-145

27. Bruckman A, Bandlow A (2003) Human-computer interaction for kids. In: Jacko JA, Sears A (eds) The human-computer interaction handbook: fundamentals, evolving technologies and emerging applications. L. Erlbaum Associates Inc, London, pp 428-440

28. Verhaegh J, Soute I, Kessels A, Markopoulos P (2006) On the design of Camelot, an outdoor game for children. In: Proceedings of the 2006 conference on Interaction design and children, New York, NY, USA, pp 9-16

29. Vanden Abeele V, Zaman B, Vanden Abeele M (2008) The unlikeability of a cuddly toy interface: an experimental study of preschoolers' likeability and usability of a 3D Game played with a cuddly toy versus a keyboard. In: Presented at the 2nd international conference on fun and games, vol 5294. Eindhoven, The Netherlands, pp 118-131 
30. Eisenberg M, Eisenberg A, Gross M, Kaowthumrong K, Lee N, Lovett W (2002) Computationally-enhanced construction kits for children: prototype and principles. In: Proceedings of ICLS (International conference on the learning sciences), pp 79-85

31. Buechley L, Eisenberg M, Catchen J, Crockett A (2008) The LilyPad Arduino: using computational textiles to investigate engagement, aesthetics, and diversity in computer science education. In: Proceeding of the twenty-sixth annual SIGCHI conference on Human factors in computing systems, New York, NY, USA, pp 423-432

32. Froebel F (2001) The pedagogics of the kindergarten. Kindergarten Messenger

33. Montessori M (1912) The Montessori method scientific pedagogy as applied to child education in "The children's houses. Frederick A. Stokes Co., New York

34. Piaget J (1970) Genetic epistemology. W.W. Norton Company, New York, NY, USA

35. Greenberg S, Buxton B (2008) Usability Evaluation Considered Harmful (Some of the Time). In: Proceeding of the twenty-sixth annual SIGCHI conference on human factors in computing systems

36. McNeil N, Jarvin L (2007) When theories don't add up: disentangling he manipulatives debate. Theory Pract 46(4):309

37. Triona L, Klahr D (Jan. 2003) Point and click or grab and heft: Comparing the influence of physical and virtual instructional materials on elementary school students' ability to design experiments. Department of Psychology

38. Klahr D, Triona LM, Williams C (2007) Hands on what? The relative effectiveness of physical versus virtual materials in an engineering design project by middle school children. J Res Sci Teach 44(1): 183-203

39. Manches A, O'Malley C, Benford S (2010) The role of physical representations in solving number problems: a comparison of young children's use of physical and virtual materials. Comput Educ 54:622-640

40. Do-Lenh S, Jermann P, Cuendet S, Zufferey G, Dillenbourg P (2010) Task performance vs. learning outcomes: a study of a tangible user interface in the classroom. In: Proceedings of the 5th European conference on technology enhanced learning conference on sustaining TEL: from innovation to learning and practice, Berlin, Heidelberg, pp 78-92

41. Bakker S, Antle AN, van den Hoven E (2009) Identifying embodied metaphors in children's sound-action mappings. In: Proceedings of the 8th international conference on interaction design and children. New York, NY, USA, pp 140-149

42. Wyeth P (2008) How young children learn to program with sensor, action, and logic blocks. J Learn Sci 17(4):517

43. Price S (2008) A representation approach to conceptualizing tangible learning environments. In Proceedings of the 2 nd international conference on tangible and embedded interaction, New York, NY, USA, pp 151-158

44. Price S, Falcao TP, Sheridan JG, Roussos G (2009) The effect of epresentation location on interaction in a tangible learning environment. In: Proceedings of the 3rd international conference on tangible and embedded interaction. New York, NY, USA, pp 85-92

45. Antle AN, Droumeva M, Ha D (2009) Hands on what?: comparing children's mouse-based and tangible-based interaction. In: Proceedings of the 8th international conference on interaction design and children. New York, NY, USA, pp 80-88

46. Kirsh D, Maglio P (1994) On distinguishing epistemic from pragmatic action. Cogn Sci 18(4):513-549

47. Antle AN, Droumeva M, Corness G (2008) Playing with the sound maker: do embodied metaphors help children learn? In: Proceedings of the 7th international conference on interaction design and children. New York, NY, USA, pp 178-185
48. Farr W, Yuill N, Raffle H (2010) Social benefits of a tangible user interface for children with autistic spectrum conditions. Autism 14(3):237-252

49. Farr W, Yuill N, Harris E, Hinske S (2010) In my own words: configuration of tangibles, object interaction and children with autism. In: Proceedings of the 9th international conference on interaction design and children. New York, NY, USA, pp 30-38

50. Garzotto F, Bordogna M (2010) Paper-based multimedia interaction as learning tool for disabled children. In: Proceedings of the 9th international conference on interaction design and children. New York, NY, USA, pp 79-88

51. Hengeveld B, Hummels C, Overbeeke K, Voort R, van Balkom $\mathrm{H}$, de Moor J (2009) Tangibles for toddlers learning language. In: Proceedings of the 3rd international conference on tangible and embedded interaction, New York, NY, USA, pp 161-168

52. Horn MS, Solovey ET, Crouser RJ, Jacob RJK (2009) Comparing the use of tangible and graphical programming languages for informal science education

53. Parkes AJ, Raffle HS, Ishii H (2008) Opobo in the wild: longitudinal evaluations of educators appropriating a tangible interface. In: Proceeding of the twenty-sixth annual SIGCHI conference on human factors in computing systems, New York, NY, USA, pp 1129-1138

54. Hassenzahl M (2004) The thing and I: understanding the relationship between user and product. In: Blythe M, Overbeeke K, Monk A, Wright P, Norwell M (eds) Funology: from usability to enjoyment. Kluwer Academic Publishers, USA, pp 31-41

55. Sweetser P, Wyeth P (2005) GameFlow: a model for evaluating player enjoyment in games. Comput Entertain (CIE) 3(3):1-24

56. Takatalo J, Häkkinen J, Lehtonen M, Kaistinen J, Göte N (2010) Presence, involvement and flow in digital games. In: Evaluating user experience in games, 1st edn. Springer, London, p 277

57. Jordan PW (2002) Designing pleasurable products: an introduction to the new human factors. Taylor \& Francis, London, UK

58. Norman DA (2003) Emotional design: why we love (or hate) everyday things, 1st edn. Basic Books, New York, USA

59. IJsselsteijn W, de Kort YAW, Poels K The game experience questionnaire: development of a self-report measure to assess the psychological impact of digital games. Manuscript in Preparation (in preparation)

60. Skalski P, Lange RL, Tamborine R, Shelton AK (2007) Mapping the road to fun: natural video game controllers, presence, and game enjoyment. In: Mapping the road to fun: natural video game controllers, presence, and game enjoyment, Annual meeting of the international communication Association, San Francisco, CA. San Francisco, CA

61. Zaman B (2007) Introducing contextual laddering to evaluate the likeability of games with children. Cogn Technol Work 10(2):107-117

62. Vanden Abeele V, Gajadhar B, De Schutter B (2009) Gaming naturally is more fun together: the influence of controller type on player experience. In: Advances in computing entertainment/ digital interactive media entertainment and arts, Athens, Greece, October 29-31

63. Bianchi-Berthouze N (2008) Body movement as a modality for supporting positive experience in HCI. In: Exertion interface workshop at $\mathrm{CHI}$

64. Lindley SE, Couteur JL, Bianchi-Berthouze N (2008) Stirring up experience through movement in game play: effects on engagement and social behaviour. In: Proceeding of the twenty-sixth annual SIGCHI conference on human factors in computing systems. Florence, Italy, pp 511-514

65. Forlizzi J, Battarbee K (2004) Understanding experience in interactive systems. In: Proceedings of the 5th conference on designing interactive systems: processes, practices, methods, and techniques, Cambridge, MA, USA, pp 261-268 
66. Mandryk R, Inkpen K, Calvert T (2006) Using psychophysiological techniques to measure user experience with entertainment technologies. Behav Inf Technol 25(2):141-158

67. Mandryk R L, Inkpen KM (2004) Physiological indicators for the evaluation of co-located collaborative play. In: Proceedings of the 2004 ACM conference on computer supported cooperative work, Chicago, Illinois, USA, pp 102-111

68. Ravaja N, Saari T, Turpeinen M, Laarni J, Salminen M, Kivikangas M (2006) Spatial presence and emotions during video game playing: does it matter with whom you play? Presence Teleoper Virtual Environ 15(4):381-392

69. Bianchi-Berthouze N, Kim WW, Patel D (2007) Does body movement engage you more in digital game play? and why? In: Proceedings of the 2nd international conference on Affective computing and intelligent interaction. Lisbon, Portugal, pp 102-113

70. Zaman B, Abeele VV (2007) Towards a likeability framework that meets child-computer interaction \& communication sciences. In: Proceedings of the 6th international conference on interaction design and children-IDC luc0lu8217\{\}07. Aalborg, Denmark, pp 1-8

71. Soute I, Kaptein M, Markopoulos P (2009) Evaluating outdoor play for children: virtual vs. tangible game objects in pervasive games. In: Proceedings of the 8th international conference on interaction design and children, New York, NY, USA, pp 250-253

72. Wyeth P (2006) Ethnography in the kindergarten: examining children's play experiences. In: Proceedings of the SIGCHI conference on human factors in computing systems, Montréal, Québec, Canada, pp 1225-1228

73. Johnson DM, Wiles J, Sweetser P, Hollingsworth KM, Gardner JA (2009) The inherent appeal of physically controlled peripherals. 2002. [Online]. Available: http://eprints.qut.edu.au/6687/. Accessed 13 Mar 2009

74. Limperos AM, Schmierbach MG, Kegerise AD, Dardis FE (2011) Gaming across different consoles: exploring the influence of control scheme on game-player enjoyment. Cyberpsychol Behav Soc Netw. doi:10.1089/cyber.2010.0146

75. Bowman ND, Boyan A (2008) Cognitive skill and presence predict flow in natural mapped video games. In: Paper presented at, Montreal, Quebec, Canada

76. Fernaeus Y, Tholander J (2006) Finding design qualities in a tangible programming space. In: Proceedings of the SIGCHI conference on human factors in computing systems, New York, NY, USA, pp 447-456

77. Marshall P et al. (2009) Fighting for control: children's embodied interactions when using physical and digital representations. In: Proceedings of the 27th international conference on human factors in computing systems, New York, NY, USA, pp 2149-2152

78. Price S, Sheridan JG, Pontual Falcão T (2010) Action and representation in tangible systems: implications for design of learning interactions. In: Proceedings of the fourth international conference on tangible, embedded, and embodied interaction, New York, NY, USA, pp 145-152
79. Hornecker E, Buur J (2006) Getting a grip on tangible interaction: a framework on physical space and social interaction. In: Proceedings of the SIGCHI conference on human factors in computing systems, Montréal, Québec, Canada, pp 437-446

80. Suzuki H, Kato H, (1995) Interaction-level support for collaborative learning: AlgoBlock-an open programming language. In: The first international conference on computer support for collaborative learning, Hillsdale, NJ, USA, pp 349-355

81. Ryokai K,Cassell J (1999) StoryMat: a play space for collaborative storytelling. In $\mathrm{CHI} 99$ extended abstracts on human factors in computing systems, New York, NY, USA, pp 272-273

82. Weller MP, Do EY-L, Gross MD (2009) State machines are child's play: observing children ages 9 to 11 playing escape machine. In: Proceedings of the 8th international conference on interaction design and children, Como, Italy, pp 170-173

83. Scharf F, Winkler T, Herczeg M, (2008) Tangicons: algorithmic reasoning in a collaborative game for children in kindergarten and first class. In: Proceedings of the 7th international conference on interaction design and children, Chicago, Illinois, pp 242-249

84. Johnson MP,Wilson A, Blumberg B, Kline C, Bobick A (1999) Sympathetic interfaces: using a plush toy to direct synthetic characters. pp 152-158

85. Bruikman H, van Drunen A, Huang H, Vakili V (2009) Lali: exploring a tangible interface for augmented play for preschoolers. In: Proceedings of the 8th International Conference on interaction design and children, Como, Italy, pp 174-177

86. Xu D (2007) Design and evaluation of tangible interfaces for primary school children. In: Proceedings of the 6th international conference on interaction design and children, New York, NY, USA, pp 209-212

87. Fails JA, Druin A, Guha ML, Chipman G, Simms S, Churaman W (2005) Child's play: a comparison of desktop and physical interactive environments. In: Proceedings of the 2005 conference on interaction design and children. Boulder, Colorado, pp 48-55

88. Wyeth P (2007) Agency, tangible technology and young children. In: Proceedings of the 6th international conference on interaction design and children. Aalborg, Denmark, pp 101-104

89. Göttel T (2007) ProBoNO: transferring knowledge of virtual environments to real world situations. In: Proceedings of the 6th international conference on interaction design and children. Aalborg, Denmark, pp 81-88

90. Metaxas G, Metin B, Schneider J, Shapiro G, Zhou W, Markopoulos P (2005) SCORPIODROME: an exploration in mixed reality social gaming for children. In: Proceedings of the 2005 ACM SIGCHI international conference on advances in computer entertainment technology, New York, NY, USA, pp 229-232

91. Kirk D, Sellen A, Taylor S, Villar N, Izadi S (2009) Putting the physical into the digital: issues in designing hybrid interactive surfaces. In: Proceedings of the 23rd British HCI Group Annual conference on people and computers: celebrating people and technology, Swinton, UK, pp 35-44

92. Mazalek A, Van den hoven E (2009) Framing tangible interaction frameworks. Artif Intell Eng Des Anal Manuf 23:225-235 